\title{
TGF $\beta-1$ and TGFBR2 polymorphisms, cooking oil fume exposure and risk of lung adenocarcinoma in Chinese nonsmoking females: a case control study
}

Yangwu Ren ${ }^{1,2}$, Zhihua Yin ${ }^{1,2}$, Kun Li $i^{1,2}$, Yan Wan ${ }^{1,2}$, Xuelian Li ${ }^{1,2}$, Wei Wu ${ }^{1,2}$, Peng Guan ${ }^{1,2}$ and Baosen Zhou ${ }^{1,2^{*}}$

\begin{abstract}
Background: Transforming growth factor- $\beta$ (TGF- $\beta$ ) plays an important role in regulating cellular functions, and many studies have demonstrated important roles for TGF- $\beta$ in various cancers. Single nucleotide polymorphisms (SNPs) of TGF- $\beta$ may influence lung carcinogenesis. The aim of this study was to test whether TGF- $\beta 1$ C509T and TGF- $\beta$ receptor II (TGFBR2) G-875A polymorphisms were associated with lung adenocarcinoma in nonsmoking females.

Methods: A hospital-based case-control study was performed in Chinese nonsmoking females. Genotyping was performed using TaqMan SNP genotyping assay, and demographic data and environmental exposure were collected by trained interviewers after informed consents were obtained.

Results: A total of 272 (95.4\%) cases and 313 (99.4\%) controls were successfully genotyped, and the results showed that the polymorphic allele frequencies of C509T and G875A were similar among lung adenocarcinoma patients and controls ( $P=0.589$ and 0.643 , respectively). However, when the data were stratified for cooking oil fume exposure, the TT genotype of the TGFB1 C509T polymorphism showed a significantly decreased risk for lung adenocarcinoma compared with the CC genotype (adjusted $O R=0.362,95 \% C l=0.149-0.878, P=0.025$ ).

Conclusions: TGF- $\beta 1$ gene C509T polymorphism might be associated with decreased risk of lung adenocarcinoma in Chinese females exposed to cooking oil fumes, but no association was observed TGFBR2 gene G875A polymorphism.
\end{abstract}

Keywords: Transforming growth factor- $\beta$, Lung adenocarcinoma, Polymorphisms, Nonsmoking females

\section{Background}

Lung cancer is one of the leading causes of cancer related death in males and females [1]. Smoking is a major risk factor in lung cancer development, and is responsible for approximately $80 \%$ of all lung cancers [2]. However, smoking alone cannot fully explain the epidemiologic characteristics of lung cancer. Epidemiological evidence has shown that only $20 \%$ smokers develop lung cancer [3]. In addition, unlike smokers common with squamous cell carcinomas, nonsmokers

\footnotetext{
* Correspondence: bszhou@mail.cmu.edu.cn

'Department of Epidemiology, School of Public Health, China Medical University, No. 77 Puhe Road, Shenyang North New Area, Shenyang, Liaoning, People's Republic of China

${ }^{2}$ Liaoning Provincial Department of Education, Key Laboratory of Cancer Etiologic and Prevention (China Medical University), Liaoning 110122, China
}

especially females were more likely to have adenocarcinoma [4]. Furthermore, the incidence and death rate of lung cancer is now declining in men, while continuing to increase in women. Thus, for the nonsmoking female population, it is more important to study the impact factors of lung adenocarcinoma.

Transforming growth factor- $\beta$ (TGF- $\beta$ ) proteins represent an important family of cytokines that play an important role in regulating cellular functions such as cell proliferation, differentiation, apoptosis, adhesion, invasion and immune response [5-8]. Among the three TGF- $\beta$ isoforms expressed in mammals, including TGF- $\beta 1$, TGF$\beta 2$ and TGF- $\beta 3$, TGF- $\beta 1$ is the most commonly expressed and abundant form in carcinogenesis [6]. TGF- $\beta 1$ exerts its effects by binding to TGF- $\beta$ receptor II (TGFBR2) and 
is associated with the activation of TGF- $\beta$ receptor I (TGFBR1) and downstream signaling $[6,8]$. Accumulating evidence has demonstrated that TGF- $\beta$ signaling plays a dual role in carcinogenesis. TGF- $\beta$ acts as a tumor suppressor by inhibiting cell proliferation or promoting cell differentiation and apoptosis in the early stage of cancer, and as a tumor promoter by promoting tumor cell invasion, dissemination and immune evasion in advanced stages [5-8].

Several genetic variants in TGF- $\beta 1$ and TGF- $\beta 2$ genes and receptors have been identified. The most studied TGF- $\beta 1$ genetic variant is the C509T polymorphism, which was reported to increase the plasma level of TGF$\beta 1$ by influencing its transcriptional activation [9]. Recent studies have identified a relationship between this polymorphism and the risk of cancer in prostate cancer [10], esophageal cancer [11], breast cancer [12], gastric cancer [13] and lung cancer $[14,15]$. However, in lung cancer-focused studies, the results were inconsistent. The common G875A polymorphism in the promoter region of TGFBR2 is also associated with transcriptional activation of the gene [16]. To the best of our knowledge, there has been no report on the TGFBR2 G875A polymorphism in lung adenocarcinoma.

Our previous study showed that cooking oil fume exposure was a risk factor for lung adenocarcinoma in Chinese nonsmoking females [17,18]. Furthermore, cooking oil fume increased TGF- $\beta 1$ secretion in lung epithelial cells [19]. Therefore, we speculated that cooking oil fume exposure may show an interaction with TGF- $\beta 1$ in lung adenocarcinoma development. To test whether the two polymorphisms in TGF- $\beta 1$ and TGFBR2 were associated with lung adenocarcinoma, a hospital-based case-control study was performed in Chinese nonsmoking females.

\section{Methods}

Study subjects and data collection

Cases and controls for this study have been described previously [17]. Briefly, we identified newly diagnosed nonsmoking female patients with histologically confirmed lung adenocarcinoma from January 2002 to November 2007. Controls were selected from cancer-free female patients with other lung diseases such as bronchitis, pneumonias, fibrosis, sarcoidosis, and chronic obstructive pulmonary disease. Controls were frequency matched to cases on age ( \pm 5 years) and none were smokers. All subjects were all unrelated Han Chinese. This investigation was approved by the Institutional Review Board of China Medical University. After informed consent was obtained from each, cases and controls were interviewed in person to collect demographic data and environmental exposure information by trained interviewers, including demographic characteristics, passive smoking, cooking oil fume exposure, fuel smoke exposure, family history of cancer, occupational exposure and dietary habits. Individuals who had smoked less than 100 cigarettes in their lifetime were defined as nonsmokers. Participants who engaged in frying or deep-frying in the kitchen more than two times each week with reported eye or throat irritation were defined with cooking oil exposure.

\section{DNA isolation and genotyping}

Genomic DNA was extracted from peripheral blood using Proteinase $\mathrm{K}$ digestion and standard phenolchloroform methods. Genotyping was performed on the Applied Bio-systems 7500 FAST Real-Time PCR System (Foster City, CA, USA) using TaqMan single nucleotide polymorphism (SNP) genotyping assay in a $10 \mu \mathrm{L}$ total reaction volume containing $5 \mu \mathrm{L} 2 \times$ TaqMan Genotyping Master mix (Affymetrix Inc., Cleveland, Ohio, USA), $0.5 \mu \mathrm{L}$ primers and probes (Applied Biosystems, assay ID: C_8708473_10 and C_27491740_10) and $2 \mu \mathrm{L}$ DNA $(15-25 \mathrm{ng} / \mu \mathrm{L})$. After an initial denaturation at $95^{\circ} \mathrm{C}$ for $10 \mathrm{~min}$, DNA was amplified by 47 cycles of $92^{\circ} \mathrm{C}$ for $30 \mathrm{~s}$, and $62^{\circ} \mathrm{C}$ for $1 \mathrm{~min}$. Ten percent of all samples were randomly selected and genotyped again for quality control.

\section{Statistical analysis}

Statistical analyses were performed using SPSS version 16.0 software (SPSS Inc., Chicago, IL). A value of $P<0.05$ was considered statistically significant. Deviations from the Hardy-Weinberg equilibrium for each SNP were assessed using the Pearson $\chi^{2}$ test. The characteristics of the patients with lung adenocarcinoma and the controls were compared using Pearson $\chi^{2}$ test. The odds ratio $(O R)$ and its $95 \%$ confidence interval $(C I)$ with adjustment for age were obtained by logistic regression method to determine the correlation between the two polymorphisms, exposure information and the risk of lung adenocarcinoma.

\section{Results}

Genomic DNA samples were extracted from 285 lung adenocarcinoma cases and 315 cancer-free controls. A total of 63 samples ( 31 cases and 32 controls) were randomly selected for genotyping replication, and the concordance rate was $100 \%$. A final 272 cases and 313 controls were successfully genotyped and included for further analyses. The demographic variables and environmental risk factors of the patients are listed in the Table 1. All cases were lung adenocarcinoma patients and females. There were no significant differences between the cases and controls in the distribution of age, income, education, family history of cancer, passive smoking and fuel smoke exposure. However, more cooking oil fume exposure was reported in the cases group (crude- $O R=1.554,95 \% C I=1.092-2.221, P=0.013$ ). 
Table 1 Selected variable in cases and controls

\begin{tabular}{llll}
\hline Variable & Cases n (\%) & Controls n (\%) & $\boldsymbol{P}$ \\
\hline Sample size & 272 & 313 & \\
Age (years) & $54.0 \pm 12.1$ & $54.2 \pm 9.1$ & 0.825 \\
Income (yuan/mouth) & $622.4 \pm 377.2$ & $561.0 \pm 388.1$ & 0.073 \\
Education & & & 0.945 \\
Never & 24 & 27 & \\
Elementary school & 129 & 156 & \\
Junior school & 79 & 85 & \\
Senior school and upwards & 40 & 45 & 0.570 \\
Family history of cancer & 35 & 33 & 0.683 \\
Passive smoking & $161(59.2 \%)$ & $178(56.9 \%)$ & 0.013 \\
Fuel smoke exposure & $78(28.7 \%)$ & $85(27.2 \%)$ & \\
Cooking oil fume exposure & $98(36.0 \%)$ & $83(26.5 \%)$ & \\
\hline
\end{tabular}

The genotype and polymorphic allele frequencies of TGF- 31 C509T and TGFBR2 G875A polymorphisms of the cases and controls are shown in Table 2. The genotype distributions of both polymorphisms among the controls were in Hardy-Weinberg equilibrium $(P=0.528$ and 0.361 for TGF- $\beta 1$ C509T and TGFBR2 G875A, respectively). No differences of genotypes for TGF- $\beta 1$ C509T and TGFBR2 G875A between the cases and the controls were detected ( $P=0.589$ and 0.643 , respectively) or polymorphic allele frequencies $(P=0.451$ and 0.731 , respectively). However, when we performed the combined

Table 2 TGFB1 C-509T and TGFBR2 G-875A polymorphisms and lung adenocarcinoma risk

\begin{tabular}{|c|c|c|c|c|c|}
\hline Polymorphism & Cases & Controls & $\mathrm{OR}_{\mathrm{adg}}$ & $95 \% \mathrm{Cl}$ & $P$ \\
\hline \multicolumn{6}{|l|}{ TGF- $\beta 1$ C-509T } \\
\hline $\mathrm{CC}$ & $78(28.7)$ & $79(25.2)$ & 1.0 & & \\
\hline$C T$ & 138(50.7) & $162(51.8)$ & 0.847 & $0.574-1.249$ & 0.402 \\
\hline$\pi$ & $56(20.6)$ & $72(23.0)$ & 0.768 & $0.480-1.228$ & 0.270 \\
\hline $\mathrm{CT} / \mathrm{TT}$ & 194(71.3) & 234(74.8) & 0.822 & $0.569-1.188$ & 0.298 \\
\hline C & 294(54.0) & $320(51.1)$ & 1.0 & & \\
\hline T & 250(46.0) & $306(48.9)$ & 0.878 & $0.697-1.106$ & 0.270 \\
\hline \multicolumn{6}{|l|}{ TGFBR2 G-875A } \\
\hline GG & 182(66.9) & $202(64.5)$ & 1.0 & & \\
\hline GA & $80(29.4)$ & 102(32.6) & 0.865 & $0.605-1.237$ & 0.427 \\
\hline AA & $10(3.7)$ & $9(2.9)$ & 1.223 & $0.486-3.078$ & 0.669 \\
\hline GA/AA & $90(33.1)$ & $111(35.5)$ & 0.895 & $0.634-1.263$ & 0.528 \\
\hline G & 444(81.6) & $506(80.8)$ & 1.0 & & \\
\hline A & 100(18.4) & $120(19.2)$ & 0.946 & $0.704-1.271$ & 0.711 \\
\hline \multicolumn{6}{|c|}{ Combined analysis } \\
\hline 0 Variant locus & 54(19.9) & $42(13.4)$ & 1.0 & & \\
\hline 1Variant locus & 152(55.9) & 197(62.9) & 0.591 & $0.374-0.935$ & 0.025 \\
\hline 2 Variant locus & $66(24.3)$ & 74(23.6) & 0.675 & $0.399-1.141$ & 0.142 \\
\hline
\end{tabular}

Abbreviation: $O R_{\text {adg }}$ age-adjusted odds ratio, $\mathrm{Cl}$ confidence interval. analyses according to the number of variant loci for these two SNPs (Table 2), those with one variant locus had a decreased risk of lung adenocarcinoma. However, this was not the case for carriers of two variant loci (age-adjusted $O R=0.591,95 \% C I=0.374-0.935, P=0.025$ for subjects carrying one variant locus; age-adjusted $O R=0.675,95 \% C I=0.399-1.141, P=0.142$ for subjects carrying two variant loci).

In analysis stratified by cooking oil fume exposure, no association was found between the TGF- 31 C509T polymorphism and the risk of lung adenocarcinoma in subjects without exposure to cooking oil fumes (Table 3). However, individuals exposed to cooking oil fumes with TT genotype were at a significantly decreased risk of lung adenocarcinoma compared with those with the CC genotype (age-adjusted $O R=0.362$, 95\% $C I=0.149-0.878$, $P=0.025)$ and in a dose-response manner $\left(\chi^{2}=4.558\right.$, $P=0.033)$. Regarding the TGFBR2 G875A polymorphism, no difference of genotype distribution between the two groups was detected. In stratified analyses by fuel smoke exposure and passive smoking status, as shown in Table 4 and Table 5, a nonsignificant association between the two polymorphisms and lung adenocarcinoma was observed. To evaluate the interaction of genetic polymorphism with cooking oil fume exposure in lung adenocarcinoma, a logistic regression was performed; the crude $O R$ and ageadjusted $O R$ value for the TT gene type with cooking oil fume exposure were 0.331 (95\% $C I=0.116-0.942, P=0.038$ ) and 0.343 (95\% CI=0.12-0.976, $P=0.045)$, respectively (data not shown). The $P$ values for the interaction of TGF$\beta 1$ and TGFBR2 with cooking oil fume exposure were 0.046 and 0.005 , respectively.

For multiple comparisons, a Bonferroni correction was performed. We genotyped 11 SNPs on these subjects, involving 106 subsequent analyses in a total of five studies, including four previously published studies [17,18,20,21] and the current study. The adjusted statistically significant level was $4.72 \times 10^{-4}$, and therefore all the associations between polymorphisms and lung adenocarcinoma were not statistically significant in the study.

\section{Discussion}

Lung cancer is currently the most common malignancy in the world, and adenocarcinoma is most common in females, especially in those who have never smoked. To explore mechanisms involved in lung adenocarcinoma, we investigated the influence of the TGF- $\beta 1$ and TGFBR2 polymorphisms on the risk of lung adenocarcinoma in a population-based case-control study. The TGF- $\beta 1$ C509T polymorphism was significantly associated with the risk of lung adenocarcinoma in individuals exposed to cooking oil fumes, and protective effects were observed in a dose-response manner. This finding suggests that the TGF- $\beta 1$ C509T polymorphism could be used as genetic 
Table 3 TGF- $\beta 1$ C-509T and TGFBR2 G-875A polymorphisms and lung adenocarcinoma risk, stratified by cooking oil fume exposure

\begin{tabular}{|c|c|c|c|c|c|c|c|c|c|c|c|}
\hline \multirow[t]{2}{*}{ Polymorphism } & \multicolumn{5}{|c|}{ Exposure to cooking oil fume } & \multicolumn{5}{|c|}{ Non exposure to cooking oil fume } & \multirow[t]{2}{*}{$P_{\text {interaction }}$} \\
\hline & Cases & Controls & $\mathrm{OR}_{\mathrm{adg}}$ & $95 \% \mathrm{Cl}$ & $P$ & Cases & Controls & $\mathrm{OR}_{\mathrm{adg}}$ & $95 \% \mathrm{Cl}$ & $P$ & \\
\hline TGF- $\beta 1$ C-509T & & & & & & & & & & & 0.046 \\
\hline $\mathrm{CC}$ & 31 & 20 & 1.0 & & & 47 & 59 & 1.0 & & & \\
\hline CT & 54 & 40 & 0.887 & $0.441-1.784$ & 0.737 & 84 & 122 & 0.841 & $0.523-1.354$ & 0.477 & \\
\hline$\pi$ & 13 & 23 & 0.362 & $0.149-0.878$ & 0.025 & 43 & 49 & 1.065 & $0.606-1.870$ & 0.827 & \\
\hline $\mathrm{CT} / \mathrm{TT}$ & 67 & 63 & 0.693 & $0.358-1.342$ & 0.277 & 127 & 171 & 0.906 & $0.578-1.420$ & 0.666 & \\
\hline TGFBR2 G-875A & & & & & & & & & & & 0.005 \\
\hline GG & 59 & 60 & 1.0 & & & 123 & 142 & 1.0 & & & \\
\hline $\mathrm{GA}$ & 34 & 23 & 1.451 & $0.761-2.766$ & 0.258 & 46 & 79 & 0.674 & $0.435-1.047$ & 0.079 & \\
\hline AA & 5 & 0 & & & & 5 & 9 & 0.629 & $0.205-1.929$ & 0.417 & \\
\hline GA/AA & 39 & 23 & 1.664 & $0.883-3.136$ & 0.115 & 51 & 88 & 0.670 & $0.439-1.022$ & 0.063 & \\
\hline
\end{tabular}

Abbreviation: $O R_{a d g}$ age-adjusted odds ratio, $\mathrm{Cl}$ confidence interval.

susceptibility marker for early diagnosis. The 5-year survival rate of lung cancer patients was only $16 \%$, but the survival rate of clinical stage I could reach 59\% [22]. This indicates that early diagnosis may increase survival and improve the quality of life for lung cancer patients.

In the current study, the frequencies of the C509T and G875A alleles among the healthy controls were 0.489 and 0.192 , respectively, similar to previous studies in a Chinese population $[9,11,13,23]$. Although the frequencies of CT and TT homozygotes among lung adenocarcinoma patients were lower than those in the control group $(50.7 \%$ vs. $51.8 \%$ in CT, $20.6 \%$ vs. $23.0 \%$ in TT, respectively), no significant association between the TGF- $\beta 1$ C509T polymorphism and the risk of lung cancer was found. This result was different from the study of Kang et al. [14], but similar to the findings of Park et al. [15]. Several studies showed that TGF- $\beta 1$ C509T polymorphisms are associated with TGF- $\beta 1$ production [9,14,24-26]. Grainger et al. [24] reported that the variant $\mathrm{T}$ allele at C509T was associated with higher plasma levels, and the TT homozygote was associated with highest plasma levels. Luedecking et al. [26] reported that the variant $\mathrm{T}$ allele was associated with increased transcriptional activity. However, identical conclusions were reported by Wang et al. [9] and Peng et al. [23], who found that the $\mathrm{C}$ allele rather than $\mathrm{T}$ allele was associated with higher plasma levels and transcriptional activity, respectively. Differences in ethnic background and genetic heterogeneity in different cancers may be the main reason for these different results.

TGFBR2 is a key receptor in regulating the TGF- $\beta$ signaling pathway by binding to TGF- $\beta$ and activating TGFBR1, so mutations in TGFBR2 may inactivate or activate the TGF- $\beta$ signaling pathway $[5,6]$. To date, many mutations in the TGFBR2 promoter have been reported $[27,28]$ that may contribute to reduced receptor

Table 4 TGF- $\beta 1$ C-509T and TGFBR2 G-875A polymorphisms and lung adenocarcinoma risk, stratified by fuel smoke exposure

\begin{tabular}{|c|c|c|c|c|c|c|c|c|c|c|c|}
\hline \multirow[t]{2}{*}{ Polymorphism } & \multicolumn{5}{|c|}{ Exposure to fuel smoke } & \multicolumn{5}{|c|}{ Non exposure to fuel smoke } & \multirow[t]{2}{*}{$P_{\text {interaction }}$} \\
\hline & Cases & Controls & $\mathrm{OR}_{\mathrm{adg}}$ & $95 \% \mathrm{Cl}$ & $P$ & Cases & Controls & $\mathrm{OR}_{\mathrm{adg}}$ & $95 \% \mathrm{Cl}$ & $P$ & \\
\hline TGF- $\beta 1$ C-509T & & & & & & & & & & & 0.685 \\
\hline CC & 21 & 17 & 1.0 & & & 57 & 62 & 1.0 & & & \\
\hline CT & 43 & 47 & 0.706 & $0.325-1.533$ & 0.378 & 95 & 115 & 0.886 & $0.564-1.394$ & 0.601 & \\
\hline$\pi$ & 14 & 21 & 0.501 & $0.195-1.289$ & 0.152 & 42 & 51 & 0.883 & $0.512-1.523$ & 0.601 & \\
\hline $\mathrm{CT} / \mathrm{TT}$ & 57 & 68 & 0.642 & $0.305-1.353$ & 0.244 & 137 & 166 & 0.885 & $0.578-1.356$ & 0.576 & \\
\hline TGFBR2 G-875A & & & & & & & & & & & 0.922 \\
\hline GG & 61 & 57 & 1.0 & & & 121 & 145 & 1.0 & & & \\
\hline GA & 15 & 24 & 0.594 & $0.280-1.257$ & 0.173 & 65 & 78 & 0.987 & $0.655-1.488$ & 0.951 & \\
\hline $\mathrm{AA}$ & 2 & 4 & 0.465 & $0.082-2.648$ & 0.388 & 8 & 5 & 1.901 & $0.606-5.963$ & 0.271 & \\
\hline GA/AA & 17 & 28 & 0.574 & $0.282-1.167$ & 0.125 & 73 & 83 & 1.043 & $0.700-1.553$ & 0.837 & \\
\hline
\end{tabular}

Abbreviation: $O R_{\text {adg }}$ age-adjusted odds ratio, $\mathrm{Cl}$ confidence interval. 
Table 5 TGF- $\beta 1$ C-509T and TGFBR2 G-875A polymorphisms and lung adenocarcinoma risk, stratified by passive smoking

\begin{tabular}{|c|c|c|c|c|c|c|c|c|c|c|c|}
\hline \multirow[t]{2}{*}{ Polymorphism } & \multicolumn{5}{|c|}{ Exposure to passive smoking } & \multicolumn{5}{|c|}{ Non exposure to passive smoking } & \multirow[t]{2}{*}{$P_{\text {interaction }}$} \\
\hline & Cases & Controls & $\mathrm{OR}_{\mathrm{adg}}$ & $95 \% \mathrm{Cl}$ & $P$ & Cases & Controls & $\mathrm{OR}_{\mathrm{adg}}$ & $95 \% \mathrm{Cl}$ & $P$ & \\
\hline TGF- $\beta 1$ C-509T & & & & & & & & & & & 0.648 \\
\hline CC & 21 & 17 & 1.0 & & & 57 & 62 & 1.0 & & & \\
\hline CT & 43 & 47 & 0.706 & $0.325-1.533$ & 0.378 & 95 & 115 & 0.886 & $0.564-1.394$ & 0.601 & \\
\hline$\pi$ & 14 & 21 & 0.501 & $0.195-1.289$ & 0.152 & 42 & 51 & 0.883 & $0.512-1.523$ & 0.601 & \\
\hline $\mathrm{CT} / \mathrm{TT}$ & 57 & 68 & 0.642 & $0.305-1.353$ & 0.244 & 137 & 166 & 0.885 & $0.578-1.356$ & 0.576 & \\
\hline TGFBR2 G-875A & & & & & & & & & & & 0.213 \\
\hline GG & 61 & 57 & 1.0 & & & 121 & 145 & 1.0 & & & \\
\hline GA & 15 & 24 & 0.594 & $0.280-1.257$ & 0.173 & 65 & 78 & 0.987 & $0.655-1.488$ & 0.951 & \\
\hline AA & 2 & 4 & 0.465 & $0.082-2.648$ & 0.388 & 8 & 5 & 1.901 & $0.606-5.963$ & 0.271 & \\
\hline GA/AA & 17 & 28 & 0.574 & $0.282-1.167$ & 0.125 & 73 & 83 & 1.043 & $0.700-1.553$ & 0.837 & \\
\hline
\end{tabular}

Abbreviation: $O R_{a d g}$ age-adjusted odds ratio, $\mathrm{Cl}$ confidence interval.

expression in tumors. However, the G875A polymorphism is the only one in which minimum allele frequency was less than 0.05 in the promoter region of TGFBR2 [16], and this polymorphism was reported as associated with transcription activities of the gene [16]. To the best of our knowledge, this is the first study that focused on the relationship between TGFBR2 G875A polymorphism and lung adenocarcinoma risk. However, no association was found. Similar studies in other cancers such as gastric cancer [13] and esophageal squamous cell carcinoma [11] in Chinese populations reported different results, probably because of genetic heterogeneity in the pathogenesis of different cancers.

A previously published genome-wide association study (GWAS) on the risk of developing lung cancer among women in Asia observed no evidence of association for TGF- $\beta 1$ and TGFBR2 [29]. Our results are consistent with the GWAS findings. Additionally, in our analysis stratified by cooking oil fume exposure, a significant association between the TGF- $\beta 1$ C509T polymorphism and the risk of lung adenocarcinoma in subjects with cooking oil fume exposure was found. The published GWAS has stronger evidence and extrapolation, and the present study could provide some clues for lung cancer in the population living in the northeastern part of China. Some in vitro results support the results of our study. Previous studies have shown that exposure to cooking oil fume condensates could inhibit cell growth, increase TGF- $\beta 1$ secretion and induce oxidative stress in human lung epithelial cells [19], suggesting that TGF- $\beta 1$ may play a role in the adverse health effects of oil fumes. However, the exact molecular mechanisms are far from understood. Reactive oxygen species can lead to increased TGF- $\beta 1$ release in human lung epithelial cells [30], and Leonarduzzi et al. [31] reported that 4-hydroxy 2,3-nonenal, a major aldehyde end product of lipid peroxidation, can also induce TGF- $\beta 1$ secretion in macrophages. This indicates that TGF- $\beta 1$ may play an important role in oxidative stress induced by cooking oil fumes. In addition, benzo[a]pyrene $(\mathrm{B}[\mathrm{a}] \mathrm{P})$, a product of heated rapeseed oil, has been also demonstrated to increase TGF- $\beta 1$ mRNA levels [32]. B[a]P can lead to cell carcinogenesis by causing DNA damage [33], therefore we speculate that TGF- $\beta 1$ might act as an protector by regulating cell proliferation and apoptosis.

This study includes several limitations. First, the sample size might not be large enough to detect the low penetrance effect of the genes, especially for stratified analysis. However, we used a trend $\chi^{2}$ test to explore the dose-response manner of lung adenocarcinoma risk and TGF- $\beta 1$ C509T polymorphism in nonsmoking female exposure to cooking oil fumes, and the power of this result is 0.957 (data not shown). Second, the rate of fuel smoke exposure is $37.2 \%$, which is higher than that of other regions of China, and we did not find any association between fuel smoke and lung adenocarcinoma. We matched the controls to the cases on age and sex, and age-adjusted ORs were calculated by logistic regression to decrease potential confounding bias caused by age. Finally, hospital-based studies are likely to include some selection bias and information bias. The exposure assessment of cooking oil fume and fuel smoke was performed by subjective reports, which has limited accuracy. Further study is needed to assess these exposures using controlled measurements and instruments.

\section{Conclusions}

Our study demonstrates that the variant genotypes in the promoter of TGF- $\beta 1$ might decrease the risk of lung adenocarcinoma in females exposed to cooking oil fumes (TT vs. $C C: O R=0.362, P=0.025$ ), but no effect was observed with the TGFBR2 G875A polymorphism. However, 
because genetic polymorphisms often vary in different ethnic groups, these findings need to be confirmed in larger groups. Further studies also need to clarify the exact molecular mechanisms of interaction between cooking oil fumes and TGF- $\beta 1$.

\section{Abbreviations}

SNPs: Single nucleotide polymorphisms; TGFB1: Transforming growth factor- $\beta 1$; TGFBR2: Transforming growth factor receptorll; OR: Odds ratio; $\mathrm{Cl}$ : Confidence interval; B[a]P: Benzo[a]pyrene.

\section{Competing interests}

The authors declare that they have no competing interests.

\section{Authors' contributions}

YR designed the study, performed the data analysis and drafted the manuscript. $Z Y, X L$ and $W W$ performed blood samples and information collection. $\mathrm{KL}$ and $\mathrm{YW}$ managed the experiment. PG assisted with results interpretation and assisted with the writing. BZ provided administrative direction, assisted with results interpretation, assisted with the writing, and secured financial support for the study. All authors read and approved the final manuscript.

\section{Acknowledgements}

The authors are most grateful to all the participants in the present study. This study was supported by grant no.81272293 from National Natural Science Foundation of China.

\section{Received: 4 March 2013 Accepted: 27 March 2015}

Published online: 10 April 2015

\section{References}

1. Jemal A, Bray F, Center MM. Global Cancer Statistics. Ca-Cancer J Clin. 2011;61:69-90

2. Pesch B, Kendzia B, Gustavsson P, Jockel KH, Johnen G, Pohlabeln H, et al. Cigarette smoking and lung cancer-relative risk estimates for the major histological types from a pooled analysis of case-control studies. Int J Cancer. 2012;131:1210-9.

3. Smyth JF. Cancer genetics and cell and molecular biology. Is this the way forward? Chest. 1996;109:125S-9S

4. Zang EA, Wynder EL. Differences in lung cancer risk between men and women: examination of the evidence. J Natl Cancer Inst. 1996;88:183-92.

5. de Caestecker MP, Piek E, Roberts AB. Role of transforming growth factor-beta signaling in cancer. J Natl Cancer Inst. 2000;92:1388-402.

6. Derynck R, Akhurst RJ, Balmain A. TGF-beta signaling in tumor suppression and cancer progression. Nat Genet. 2001;29:117-29.

7. Gordon KJ, Blobe GC. Role of transforming growth factor-beta superfamily signaling pathways in human disease. Biochimica Et Biophysica Acta-Mol Basis Dis. 2008;1782:197-228.

8. Massague J. TGFbeta in Cancer. Cell. 2008;134:215-30

9. Wang H, Zhao YP, Gao CF, Ji Q, Gressner AM, Yang ZX, et al. Transforming growth factor beta 1 gene variants increase transcription and are associated with liver cirrhosis in Chinese. Cytokine. 2008:43:20-5.

10. Ewart-Toland A, Chan JM, Yuan JW, Balmain A, Ma J. A gain of function TGFB1 polymorphism may be associated with late stage prostate cancer. Cancer Epidemiol Biomark Prev. 2004;13:759-64.

11. Jin G, Deng Y, Miao R, Hu Z, Zhou Y, Tan Y, et al. TGFB1 and TGFBR2 functional polymorphisms and risk of esophageal squamous cell carcinoma: a case-control analysis in a Chinese population. J Cancer Res Clin Oncol. 2008;134:345-51.

12. Shin AS, Shu XO, Cai QY, Gao YT, Zheng W. Genetic polymorphisms of the transforming growth factor-beta 1 gene and breast cancer risk: A possible dual role at different cancer stages. Cancer Epidemiol Biomark Prev. 2005;14:1567-70.

13. Jin G, Wang L, Chen W, Hu Z, Zhou Y, Tan Y, et al. Variant alleles of TGFB1 and TGFBR2 are associated with a decreased risk of gastric cancer in a Chinese population. Int J Cancer. 2007;120:1330-5.

14. Kang HG, Chae MH, Park JM, Kim EJ, Park JH, Kam S, et al. Polymorphisms in TGF-beta1 gene and the risk of lung cancer. Lung Cancer. 2006;52:1-7.
15. Park KH, Lo Han SG, Whang YM, Lee HJ, Yoo YD, Lee JW, et al. Single nucleotide polymorphisms of the TGFB1 gene and lung cancer risk in a Korean population. Cancer Genet Cytogenet. 2006;169:39-44.

16. Seijo ER, Song H, Lynch MA, Jennings R, Qong X, Lazaridis E, et al. Identification of genetic alterations in the TGFbeta type II receptor gene promoter. Mutat Res. 2001;483:19-26.

17. Yin Z, Su M, Li X, Li M, Ma R, He Q, et al. ERCC2, ERCC1 polymorphisms and haplotypes, cooking oil fume and lung adenocarcinoma risk in Chinese non-smoking females. J Exp Clin Cancer Res. 2009;28:153.

18. Li M, Yin Z, Guan P, Li X, Cui Z, Zhang J, et al. XRCC1 polymorphisms, cooking oil fume and lung cancer in Chinese women nonsmokers. Lung Cancer. 2008;62:145-51.

19. Tung YH, Ko JL, Liang YF, Yin L, Pu Y, Lin P. Cooking oil fume-induced cytokine expression and oxidative stress in human lung epithelial cells. Environ Res. 2001;87:47-54

20. Shen L, Yin Z, Wu W, Ren Y, Li X, Zhou B. Single nucleotide polymorphism in ATM gene, cooking oil fumes and lung adenocarcinoma susceptibility in Chinese female non-smokers: a case-control study. PLoS One. 2014;9:e96911.

21. Yin Z, Cui Z, Ren Y, Zhang H, Yan Y, Zhao Y, et al. Genetic polymorphisms of TERT and CLPTM1L, cooking oil fume exposure, and risk of lung cancer: a case-control study in a Chinese non-smoking female population. Med Oncol. 2014:31:114

22. Hayat MJ, Howlader N, Reichman ME, Edwards BK. Cancer statistics, trends, and multiple primary cancer analyses from the Surveillance, Epidemiology, and End Results (SEER) Program. Oncologist. 2007;12:20-37.

23. Qi P, Chen YM, Wang H, Fang M, Ji Q, Zhao YP, et al. $-509 \mathrm{C}>\mathrm{T}$ polymorphism in the TGF-beta1 gene promoter, impact on the hepatocellular carcinoma risk in Chinese patients with chronic hepatitis B virus infection. Cancer Immunol Immunother. 2009;58:1433-40.

24. Grainger DJ, Heathcote K, Chiano M, Snieder H, Kemp PR, Metcalfe JC, et al. Genetic control of the circulating concentration of transforming growth factor type beta1. Hum Mol Genet. 1999;8:93-7.

25. Suthanthiran M, Li B, Song JO, Ding R, Sharma VK, Schwartz JE, et al. Transforming growth factor-beta 1 hyperexpression in African-American hypertensives: A novel mediator of hypertension and/or target organ damage. Proc Natl Acad Sci U S A. 2000;97:3479-84.

26. Luedecking EK, DeKosky ST, Mehdi H, Ganguli M, Kamboh MI. Analysis of genetic polymorphisms in the transforming growth factor-betal gene and the risk of Alzheimer's disease. Hum Genet. 2000;106:565-9.

27. Munoz-Antonia T, Li X, Reiss M, Jackson R, Antonia S. A mutation in the transforming growth factor beta type II receptor gene promoter associated with loss of gene expression. Cancer Res. 1996;56:4831-5.

28. Hougaard S, Norgaard P, Abrahamsen N, Moses HL, Spang-Thomsen M, Skovgaard Poulsen $\mathrm{H}$. Inactivation of the transforming growth factor beta type II receptor in human small cell lung cancer cell lines. Br J Cancer. 1999;79:1005-11.

29. Lan Q, Hsiung CA, Matsuo K, Hong YC, Seow A, Wang Z, et al. Genome-wide association analysis identifies new lung cancer susceptibility loci in never-smoking women in Asia. Nat Genet. 2012;44:1330-5.

30. Bellocq A, Azoulay E, Marullo S, Flahault A, Fouqueray B, Philippe C, et al. Reactive oxygen and nitrogen intermediates increase transforming growth factor-beta1 release from human epithelial alveolar cells through two different mechanisms. Am J Respir Cell Mol Biol. 1999;21:128-36.

31. Leonarduzzi G, Scavazza A, Biasi F, Chiarpotto E, Camandola S, Vogel S, et al. The lipid peroxidation end product 4-hydroxy-2,3-nonenal up-regulates transforming growth factor beta1 expression in the macrophage lineage: a link between oxidative injury and fibrosclerosis. FASEB J. 1997:11:851-7.

32. Zhang L, Shiverick KT. Benzo(a)pyrene, but not 2,3,7,8-tetrachlorodibenzo-pdioxin, alters cell proliferation and c-myc and growth factor expression in human placental choriocarcinoma JEG-3 cells. Biochem Biophys Res Commun. 1997;231:117-20.

33. Guengerich FP. Metabolic activation of carcinogens. Pharmacol Ther. 1992;54:17-61. 